\title{
Site Report
}

ESCC Meeting January 17, 2013

\section{Louella Panaga Enterprise Network Solutions Group Leader}

\section{UL Layrence Livermore National Laboratory}

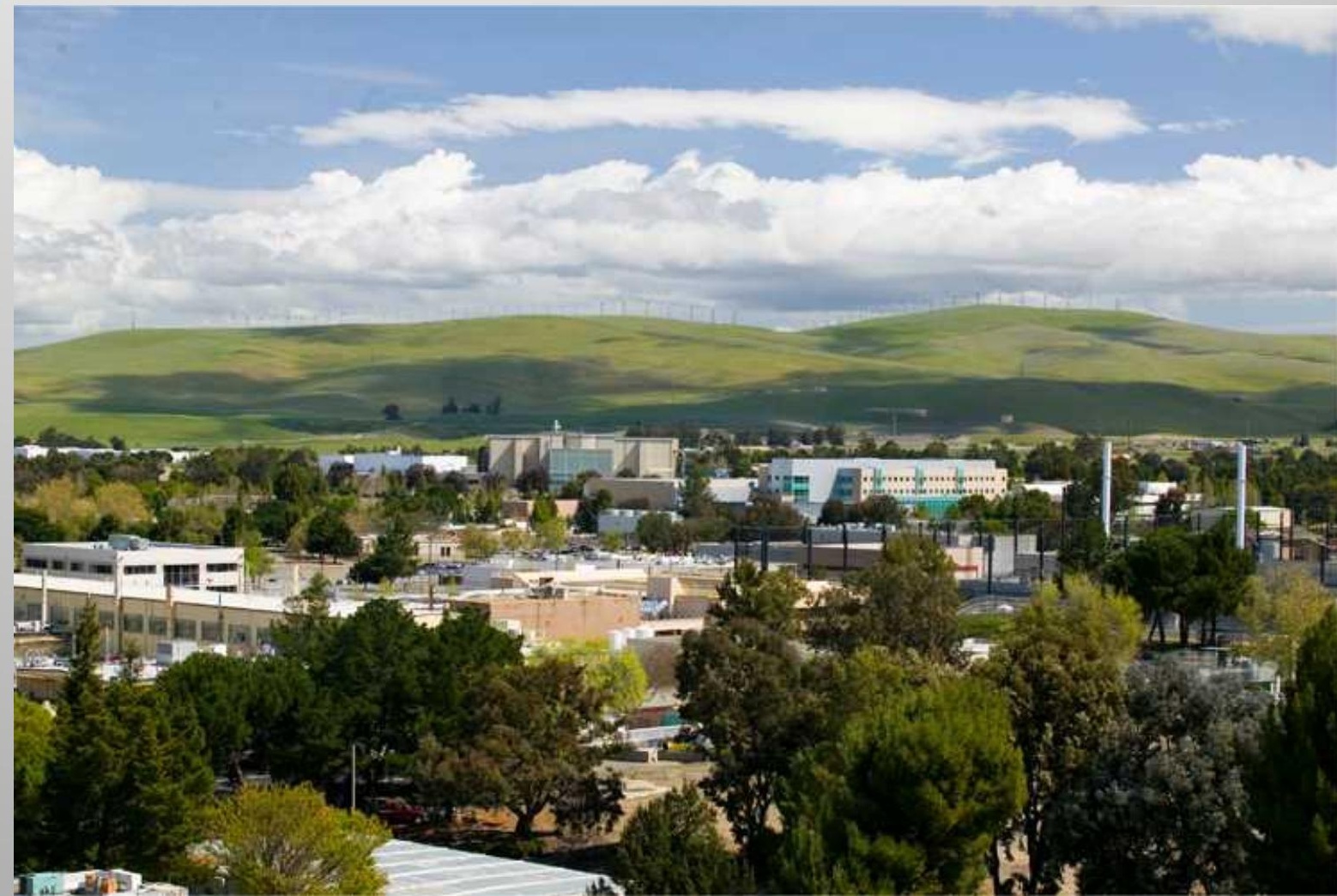




\section{Accomplishments}

- Extranet Environment

- Site-to-site VPN

- Cisco ASR1006

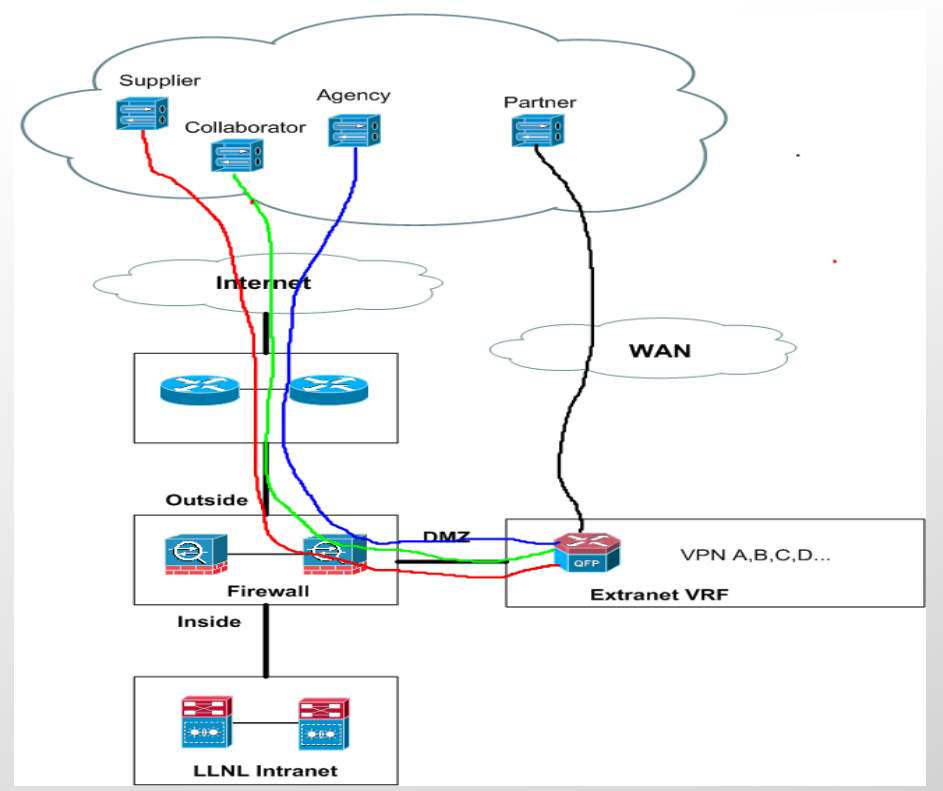

- Wireless on restricted network Proof of Concept - 2-factor auth: AD PKI Cert and HSPD-12 Card

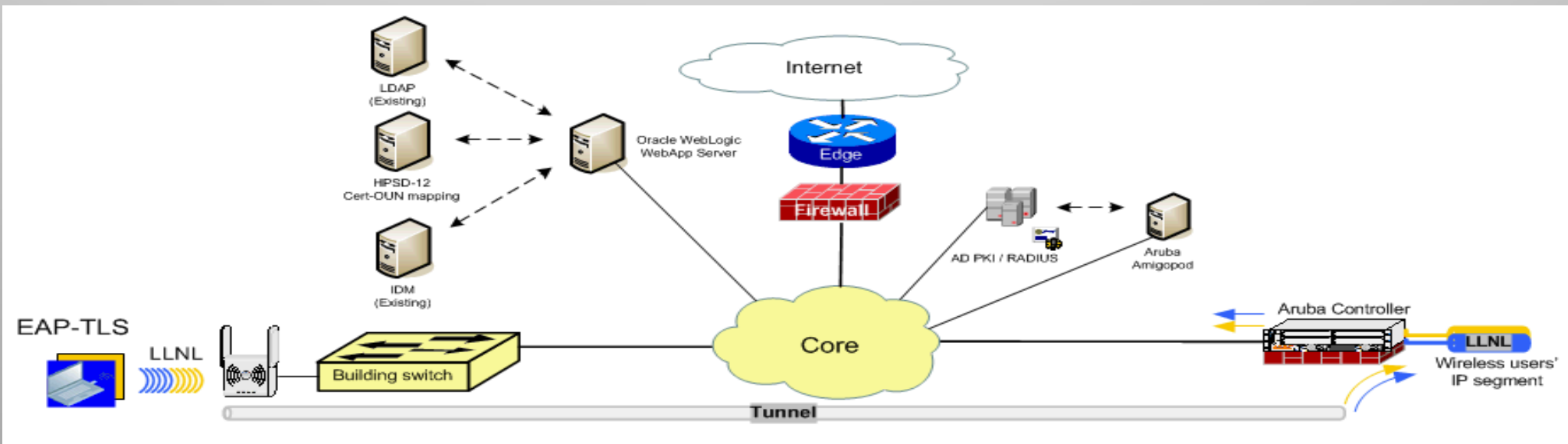




\section{On-going Projects}

- Network Refresh

- Since FY11, continuing to replace EOL equipment

- Next Generation Firewall Deployment

- Performs IPS, filters web content, restricts internet access via captive portal authentication

- Future: ssl inspection, application inspection, NAC

- Data and Voice Network Consolidation

- Video Conferencing solutions

- Telepresence systems, Jabber

- Wireless Authentication in support of mobile devices 


\section{Currently No Funding}

- IPv6 Adoption / Deployment

- Completed IPv6 Address schema

- Enabled IPv6 presence on the edge

- Defined approach, equipment, effort

- Modified Oracle backend to support home grown IPAM

- IPv6 subnets

- AAAA/v6.arpa DNS records 
느 Lawrence Livermore 